\title{
Pandemi Sonrası Oyunculuk Eğitiminde Online Teknolojilerin Kullanımı Üzerine Bir Değerlendirme
}

\section{An Evaluation of the Use of Online Technologies in Acting Courses after the Pandemic}

\author{
Emre Yalçın ${ }^{1}[$
}

'Dr. Öğr. Üyesi, Kafkas Üniversitesi Güzel Sanatlar Fakültesi, Sahne Sanatları Bölümü, Kars, Türkiye

\section{ORCID: E.Y. 0000-0003-3569-5730}

Sorumlu yazar/Corresponding author: Emre Yalçın,

Kafkas Üniversitesi Güzel Sanatlar Fakültesi, Sahne Sanatları Bölümü, Kars, Türkiye

E-posta/E-mail:yalcemre@gmail.com

Başvuru/Submitted: 06.10.2021 Revizyon Talebi/Revision Requested: 24.10.2021

Son Revizyon/Last Revision Received: 28.10.2021

Kabul/Accepted: 04.11 .2021

\section{Atıf/Citation:}

Yalçın, Emre. "Pandemi Sonrası Oyunculuk Eğitiminde Online Teknolojilerin Kullanımı Üzerine Bir Değerlendirme" Tiyatro Eleştirmenliği ve Dramaturii Bölümü Dergisi 33, (2021): 43-60. https://doi.org/10.26650/jtcd.1005652

\section{ÖZ}

Bu çalışma küresel pandemi koşullarından çıkıp normalleşme sürecine geçtiğimiz bugünlerde, olağanüstü koşulların dışında da oyunculuk eğitiminde online ders içeriklerinden faydalanabileceğine dair argümanlar oluşturmayı, konuyla ilişkili yapılacak daha gelişkin akademik tartışmaların gerekliliğini ortaya koyan veriler ve başlıklar oluşturmayı hedeflemektedir. Görüleceği üzere oyunculuk eğitiminde online eğitimin sunduğu, esnek zamanlı, mekana ve öğretmen-öğrencinin fiziksel birlikteliğine bağımlı olmayan, öğretmenin öğrenme süreçlerindeki hegemonik işlevini kırıp otodidaktik öğrenmeye yol açan olanakların önündeki en büyük engel, konuyla ilişkili katı ve kalıplaşmış düşüncelere sığınma eğilimidir. Oyunculuk eğitimini tiyatro eğitimine sabitleyen, tiyatroyu da yalnızca onun performatifliğiyle açıklayan ve bu doğrultuda online teknolojileri işlevsiz ve yozlaştırıcı olarak gören algının tartışmaya açılması, genel geçer düşüncelerin yeniden gözden geçirilmesi kritik derecede önem arz etmektedir.

Anahtar Kelimeler: Online oyunculuk eğitimi, Oyunculuk, Otodidaktizm, Ayna nöronlar, Ekran oyunculuğu

\section{ABSTRACT}

As we progress toward a release from the global pandemic conditions and a normalization process, this study aims to mount arguments about the possibility of benefiting from an online learning model for training actors aside from extraordinary conditions and to engender headlines and data that present the requirement of more advanced academic discussions in this situation. As will be seen, the main obstacle to the opportunities online education provides for acting training, which leads to flexible time, independence from space and instructor-student physical togetherness, autodidactic learning with the distortion of the instructor's hegemonic function in learning processes, is the tendency to take refuge in solid and preconceived ideas about the matter. It is of great significance to bring up for discussion the perception that pins acting training to theatre education, explains theatre only via its performance, and, accordingly, regards online technologies as functionless and degenerative. There is need to revise these mainstream notions.

Keywords: Online Acting Training, Acting, Autodidacticism, Mirror Neurons, Screen Acting 


\section{EXTENDED ABSTRACT}

Could it be possible for acting training to benefit from online class content aside from extraordinary conditions such as those experienced in the recent pandemic? There is a fundamental and rigid perception about acting training and, by predicating on theatre's ontological foundation, this perception shows the attitude of rejecting online technologies at first value regarding them as functionless or even degenerative. Considering that departments providing training for acting are mostly those of performing arts and theatre, this is an understandable situation to some extent. Theatre is a performing art. It possesses a realm of existence that is living, occurring in the here and now, and is based on the physical togetherness of the performers and the spectator. As Peggy Phelan emphasizes in her observations about performance, when being copied and reproduced or transformed to digital content, its "ontological engagement decreases" and it turns into something else. Acting training has a performative aspect. The "feedback" cycle that Erika Fischer-Lichte identifies in performance, comes to light in acting training, too. In acting classes, the roles of the students and instructors perpetually interchange. Together they compose an ensemble and, in just the same way as that which occurs in theatrical performances, this ensemble experiences different manners of physical encounter. The relationship between distance and closeness, the societal and the personal, a glance and a touch...

In the manner that Phelan and Lichte's notions support it, can the idea be argued that online education cannot be engaged for acting training regarding these ontological foundations of theatre? Or do the ontological foundations of theatre only consist of its performance? Moreover, does the fact that acting is embedded traditionally in theatre departments require us to consider theatre and acting training as being identical and interdependent to this degree? How much longer can we seek shelter in the stereotyped notions by sticking to traditional theatrical education that rejects the possibilities that online education offers, while it is obvious that today acting graduates practice their profession more in the cinema, TV, and on digital or social media platforms than on stage arts and that they require educational content for these areas?

Departing from these questions, this study aims to draw up scientific data, arguments, and points of discussion that will provide us with away to revise our mainstream ideas about the application of online educational content for acting training. Accordingly, it suggests considering the mimetic aspect of theatre as well against the stereotyped notion that rejects online education at first hand by predicating on its performative bases. Primarily, it discusses the mimetic learning processes that function with compositions such as mimicking, representation, reflection, establishing empathy, and identification, which Plato and Aristotle discussed around 2400 years ago. Thereafter, it interrogates why we do not consider online education by basing on mimesis, which is another foundation of theatre, but missed online education by taking only its performative aspect into account, while our biological device permits it in the manner 
the discovery of mirror neurons support it. Afterwards, autodidactic processes are discussed in detail, which have a significant role in acting training as in every educational field, and opportunities presented in this direction by online education are pointed out. In this regard, there is a focus on what kind of alternatives online education offers against traditional education, which cannot work beyond the physical togetherness of the student and instructor, all subject to the educational processes of the hegemonic relationship determined by the instructor and prepares the students only for stage acting after graduation. As for the last chapter, the content and practices of online acting training created in various platforms, establishments or programs are discussed. A considerable amount, quality, and variety of online practices carried out, constitute data and experiences that enable it to approach the subject with further thought. 


\section{Giriş}

Dünya çapında yaşanılan pandemi (Covid 19) ile beraber büyük bir krizin içine yuvarlanan akademik alanlardan biri de oyunculuk eğitimi olmuştur. Bugüne kadar eğitmen ve öğrencinin fiziksel bir aradalığına endeksli ve uzaktan eğitimde kullanılacak yeni iletişim teknolojilerine yabancı olan eğitmenler-öğrenciler apar topar dahil oldukları uzaktan eğitim sürecinde birçok problemle yüzleşmek durumunda kalmışlardır. Bağlantı sorunları, ev ortamındaki koşulların elverişsizliği, senkronizasyon problemleri, gerekli teknolojik alt yapıya öğrencilerin eşit bir şekilde sahip olamaması ve belki de en önemlisi olarak sahne üzerinde verilen eğitime göre geliştirilmiş müfredatların, programların ve planlamaların online eğitime adapte edilememesi gibi sorunlar bu krizin en görünür taraflarını oluşturmuştur.

Tüm bu olumsuzlukların yanında oyunculuk eğitmenleri ve öğrencileri online eğitime dair önemli deneyimler elde etmişler, karşılaştıkları sorunlara yaratıcı, deneysel ve işlevsel çözümler getirmişlerdir. Bu doğrultuda bugüne kadar daha çok kuramsal çalışmalarla gündeme gelen, iletişim teknolojilerinin hızla geliştiği dijital çağda, oyunculuk eğitiminin gittikçe daha fazla dijital platformlara taşınacağı ve online eğitimin oyunculuk eğitiminin geleceğinde önemli rol oynayacağına dair fikirler somut pratiklere dönüşmüştür. Önceleri daha çok kaydedilmiş ya da kurgulanmış videoların kullanıcılar tarafından dijital ve sanal ortamlarda izlenilmesine dayanan online eğitimde, Zoom, Microsoft Teams, Moodle gibi uygulamaların hayata geçirilmesi, canlı performansların gerçekleştiği, aynı anda bir çok öğrencinin birbirini ve eğitimciyi gözlemleyebildiği içeriklerin oluşturulabilmesini beraberinde getirmiştir.

Bu noktada şu soru akıllara geliyor: pandeminin olmadığı normal koşullarda da oyunculuk eğitiminde kuramsal derslerin yanında bazı pratik dersler online olarak sürdürülmeye devam edilebilir mi? Bu soruya ilk elden olumsuz cevap verecek çoğunluğun güçlü bir argümanı var ve bu argüman, tarih boyunca oyunculuk eğitimine yön veren tiyatro sanatının ontolojik temelleriyle bağlantılı. Buna göre tiyatro performansa dayalı bir sanattır ve canlılık bu sanatın birincil ontolojik tarafını oluşturur. Phelan'ın performans üzerine düşünceleri, tiyatro sanatı üzerinden düşünüldüğünde bu yaklaşımı daha da keskinleştirir. Buna göre şimdi ve burada gerçekleştiği için performans bittiği anda yok olmakta, kaydedilememekte, belgelenememekte, yahut korunamamaktadır. Tek yaşamı "şimdide" olduğu için temsilin temsilleri olarak işleyen dolaşım mekanizmasında var olamayıp, yeniden üretilip, çoğaltılamamaktadır. Aksi takdirde performanstan farklı bir şey olmakta, kendi ontolojisinin vaatlerini azaltmakta, hatta ona ihanet etmektedir. ${ }^{1}$ Hiç kuşkusuz oyunculuk eğitimine dair genel algıya da bu ontolojik nitelik temel oluşturur. Sahne eğitimi de, canlı kanlı, şimdi ve burada gerçekleşen, eğitmen ve öğrencilerin beş duyu organlarının da aktif olduğu haliyle sineztezik, bedensel farkındalığı üreten şekilde somatik bir fiziksel ilişkiye dayanır. Bu bağlamda oyunculuk eğitimi de performatif bir nitelik

1 Peggy Phelan, Unmarked: The Politics of Perfomance (London: Routledge,1993), 146. 
taşır ve Erika Fischer-Lichte'nin tiyatral performansta tespit ettiği "feed back döngüsü" oyunculuk eğitiminde de iş başındadır. Tıpkı performans içerisinde oyuncular ve seyircilerin arasında rollerin sürekli değiştiği gibi öğrencilerin kendi aralarında, hatta öğrenciler ve eğitmenler arasında roller değişmekte, taraflar daima birbirlerinin yerini almaktadır. Herkes her an oyuncu, her an seyirci olabilmektedir. Döngünün ikinci başlığı olarak yer alan, oyuncuların ve seyircilerin birlikte bir topluluk oluşturduğu fikri de oyunculuk eğitiminde karşılık bulur. Oyunculuk sınıfı, tapınağı sahne olan yarı ruhani bir cemaat; gündelik yaşamın bencilliklerini dışarıda bırakmak "zorunda" olan kolektif bir kimliktir. Bu kimliği yeniden ve yeniden üreten ritüellerin katılımcılarından oluşan; bedensel bir topluluktur. Bedensel bir aradalığa dayanan bu topluluk hali, yine Lichte'nin tiyatral perfomansta tespit ettiği feed back döngüsündeki karşılıklı temasın farklı biçimlerini deneyimlemeyi tetikler. Uzaklıkla yakınlık, toplumsal olanla kişisel olan ve bakış ile dokunuş arasındaki ilişki...2

Phelan'ın ve Lichte'nin performansa dair düşünceleriyle örneklendiği şekliyle, tiyatronun ontolojik temellerinden yola çıkarak "oyunculuk eğitimi uzaktan ya da online gerçekleştirilemez", düşüncesine bütünüyle varabilir miyiz? Ya da tiyatronun ontolojik temellerini yalnızca onun performatifliğiyle mi açıklayabiliriz? Dahası, yaşadığımız dijital çağ içinde oyuncuların daha çok sinema, televizyon, reklam, sosyal medya ve internet medyaları içinde sanatlarını icra ettikleri gerçeğini göz önünde bulundurursak, sahne, ses, konuşma, hareket eğitimi vs. üzerine kurulu sahne eğitimi ile oyunculuk eğitimini bu kadar özdeş kılmamız ne kadar doğru? Oyunculuk eğitiminin bugün daha çok sahne sanatları ve tiyatro bölümlerinde veriliyor olmasının doğal olarak sahneye yönelik bir eğitimi geçerli kılmasının yanında, bu eğitimleri alan mezunların çok azının sahne oyunculuğunda devam ediyor/edebiliyor olması nasıl bir çelişki ortaya koymaktadır? Tiyatro eğitimini merkeze almadan -ama aynı zamanda önemini yok saymayıponu oyunculuk eğitiminin bir parçası olarak koruyarak, dijital çağın olanaklarıyla daha gelişmiş bir oyunculuk eğitimi tasarlamak mümkün müdür? Bu çalışma, yukarıda sıraladığımız sorulara doğrudan ve kesin cevaplar oluşturmayı amaçlamıyor. Varolan problemleri ve online eğitimin sunduğu olanakları ortaya koyup oyunculuk eğitimine dair, yeni ve ideal bir modelin arayışında da değil. Ancak bu gibi sorularla beraber, ani ve sert bir şekilde gündemimize giren, ürettiği tüm problemlerin yanında akademiye önemli deneyimler kazandıran "online eğitime" dair genel geçer düşünceleri yeniden gözden geçirmeye yol açacak tartışma ve hareket noktaları oluşturmayı hedefliyor.

Bu doğrultuda çalışma ilk olarak oyunculuk eğitimini, sahne sanatları ve tiyatronun ontolojik temelleriyle açıklamaya çalışan bakışın gözden kaçırdığını düşündüğü şekilde mimesis kavramı üzerinden ilerliyor. Bugün tiyatro denilince aklımıza gelen sanatsal etkinliği ve toplumsal buluşmayı açıklamakta en az performatiflik kadar hayati ve kökensel olan mimetik nitelik, kuşkusuz oyunculuk eğitimine dair de çok şey ifade ediyor. Sonraki bölümde, oyunculuk

2 Erika Fischer-Lichte, Performatif Estetik, çev.Tufan Acil (İstanbul: Ayrıntı Yayınları, 2016), 65. 
eğitiminin formal olmayan, zaman-mekan-eğitmen bağımlılığından ya da baskısından kurtulmuş tarafı olarak, otodidaktik süreçlere odaklanılıyor ve online eğitimin otodidaktik öğrenmeye açtığı alanlar üzerinde yoğunlaşılıyor. Hemen sonrasında çalışma, oyunculuk eğitiminde online teknolojilerin sunduğu imkanları ilk elden reddeden, oyunculuk eğitimini bütünüyle sahne eğitimine sabitleyen geleneksel bakışın mesleki açıdan oyuncuların ihtiyaçlarına ne kadar cevap verdiğinden yola çıkıp alternatif pedagojik yaklaşımlara duyulan ihtiyaca işaret ediyor ve bu süreçlerde online teknolojilerin önemli bir rol oynayabileceğinin altını çiziyor. Son bölümde ise online oyunculuk eğitimine dair çeşitli pratikler ve örnekler mercek altına alınmaya çalışılıyor.

\section{Oyunculuk Eğitimi Performatif Olduğu Kadar Mimetik Bir Etkinliktir}

Batı felsefesinin ve tiyatro teorilerinin kurucu düşünürleri Platon ve sonrasında Aristoteles, mimesis'e dair bugün hala geçerli olan önemli bir tespit yapmışlardı. İnsanlar mimesis yoluyla öğreniyor, tiyatro sahnesinde olup bitenle özdeşleşiyor, zararlı duygulanımlara, tutkulara kapılıyor ya da bunlardan bütünüyle arınıyorlardı. Aristoteles'e göre şiir sanatını doğuran iki doğal nedenden birisi insanların çocukluktan itibaren taklit etmeye eğilimli olmaları, ilk temel bilgilerini taklit yoluyla elde etmeleriydi. ${ }^{3}$ Platon ise Devlet kitabında-olumsuz bir bakış açısıyla olsa da- mimesis' in insan karakterini etkileyen, değiştirip dönüştüren eğitici-öğretici gücünü etik bir çerçevede ele alıyordu. ${ }^{4}$ Platon'un ve Aristoteles' in bu tespitlerinden yaklaşık 2400 yıl sonra, 1990’larda Parma Üniversitesi'nde başlayıp günümüze kadar süren deneyler ve araştırmalar mimetik etkinliğin, taklit, temsil ya da empati yoluyla öğrenmenin ya da deneyimlemenin beynimizin farklı bölgelerinde bulunan ayna nöronlarla ilişkili biyolojik bir donanımın uzantısı olduğunu bilimsel açıdan ortaya koydular. ${ }^{5}$

Bu nöronlara ayna nöronlar denilmesinin nedeni, başkası bir hareketi gerçekleştirirken ya da fiziksel ya da duygusal bir yoğunluğun içindeyken onu gözlemleyen kişinin beyninde de aynı bölgedeki nöronların etkinleşmesiyle ilişkilidir. Yani hareketi gerçekleştiren, ya da belirgin duygulanımlara sahip kişinin nöronları, gözlemleyen kişinin nöronlarını da dolaylı olarak etkinleştirmektedir. Etkinleşen nöronların işlevleri, sanki aynada yansıtılmış gibi karşıdaki kişide de gerçekleşir. Tıpkı bir aynanın görüntüyü yansıtması gibi, kişi kendisi yapmadığı halde, karşısındakini izlerken, aynı hareketi ya da duyguyu sanki kendisi yapıyormuş/yaşıyormuş gibi beynindeki etkinliğin artması söz konusu olmaktadır. ${ }^{6}$ İzlediğimiz bir filmde oyuncunun üzerinde dolaşan bir örümcek bizi de terletir, bir sporcunun bitiş çizgisine yaklaşması bizi de heyecanlandırır, taklit yoluyla bir hareketi hemen kavrayıp uygulayabiliriz. Her birinde ayna nöronlarımız devrededir.

3 Aristotle, Poetics, trans. Anthony Kenny (Oxford: Oxford University Press, 2013), 1448b-5-10.

4 Arne Melberg, Theories of Mimesis (Cambridge: Cambridge University Press, 1995), 10-11.

5 Christian Keysers, Empatik Beyin, çev. Aybey Eper (İstanbul: Alfa Yayınları, 2011), 1-2.

6 Abdurrahman Coşkun, “Ayna Nöronlar”, Bilim ve Teknik 557 (Nisan 2014), 64-65. 
Ayna nöronların keşfinin de desteklediği şekilde, şayet mimetik etkinlik yoluyla öğrenebiliyor, empati kurabiliyorsak, başkalarının deneyimini kendi deneyimimiz olarak kolaylıkla alabiliyorsak bu, uzaktan/online gerçekleştirilen bir oyunculuk eğitiminin teorik açıdan önünün açık olduğu anlamına gelmektedir. Bu bağlamda online, senkronize ya da asenkronize, farklı medyalar, farklı iletişim teknolojileri kullanılarak gerçekleştirilecek oyunculuk eğitiminin imkansızlığı ya da işlevsizliğini ilk elden savunmak ne kadar doğrudur? Kaldı ki online eğitimden önce de eğitimciyle eğitmenin aynı uzam/zamanı paylaşmadan eğitim ilişkisi kitaplar (Stanislavski, Grotowski vb.) el yazmaları (comedia dell'arte oyuncuları) çizimler, (M.Chekhov), fotoğraflarfilmler (Grotowski, Meyerhold) ve videolar (Barba ve Odin Theatre) vasitasıyla uzaktan sürdürülmüştür. Bu durum hiçbir eğitim alanın olmadığı gibi oyunculuk eğitiminin de tek boyutlu olmadığını, online eğitimin zaten varolan otodidaktik öğrenme süreçlerinin evriminin bir aşaması olduğunu işaret etmektedir.

\section{Oyunculuk Eğitiminde Otodidaktizm Olgusu ve Online Eğitim:}

Eğitimde firsat eşitliği sağlamak, herhangi bir yerden herhangi bir zamanda eğitime devam edebilmek, eğitim maliyetlerini hem kurumlar hem de öğrenciler lehinde düşürmek, ulaşımda zaman kaybını önlemek, öğrencilerin kendi programlarını oluşturabilecekleri esnekliği kurmak, hem çalışıp hem de okuyabilmeye alan açmak, gibi başlıklar uzaktan eğitimin bütün alanlara sağladığı genel avantajlar olarak ön plana çıkmaktadır. ${ }^{7}$ Tüm bu avantajların ortak bir getirisi olarak açığa çıkan ve belki de uzaktan oyunculuk eğitiminde en kritik rolü oynayan durum, öğrencilerin kendi kendilerine öğrenme süreçlerini tetikleyebilecek formal öğretmen-öğrenci ilişkisini kıran otodidaktik süreçlere kapı aralanmasıdır. Otodidaktizm, en genel anlamıyla "bir hoca, usta ya da öğretici olmadan kendi kendine öğrenme anlamına gelmektedir. Bu

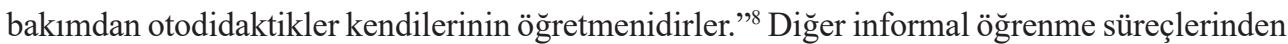
farkı bu sürecin bütünüyle öğrenen kişinin kontrolünde gelişmesidir. Otodidaktik kişi bir alana ilgi duyar, kendi çalışma materyallerini belirler, çalışma ritmini ve zamanının kendi ayarlar, yöneldiği alanın bütün derinliklerini öğrenmek, bütün inceliklerine hakim olmak için amansız bir çabaya girişir. Bu çaba içinde kütüphaneler, eğitmenler, kitaplar, internet vs. hepsi otodidaktik kişinin hizmetine girer.

Tıpkı resim, müzik, heykeltıraşlık ya da dans alanlarında olduğu gibi oyuncular da sanatlarının gereği otodidaktik süreçlere bağımlıdırlar. Formal bir sanat eğitiminde genel teknik bir bilgi öğretilir, fakat bu teknik bilginin nasıl, hangi alanlarda, hangi biçimlerde ve ne gibi bir ustalıkla kullanılacağı büyük oranda sanatçıya kalır. Bu bağlamda oyuncu adayı eğitmeninden metinleri nasıl analiz edeceğine, alt metinleri nasıl oluşturacağına, partneriyle

7 Mamjeh Sadeghi, “A Shift from Classroom to Distance Learning: Andvantages and Limitations”, International Journal of Research in English Education 4:1 (2019) 83-84. Erişim 13.09.2021 http://ijreeonline.com/article1-132-en.html http://dx.doi.org/10.29252/ijree.4.1.80

8 “Autodidacticism”, erişim 03 Temmuz 2019, https:/educalingo.com/en/dic-en/autodidacticism 
nasıl ilişki kuracağına, konsantrasyonunu nasıl koruyup, dramaturjiye nasıl hakim olacağına dair çok şey öğrenir. Fakat mezun olduktan sonra oyunculuğa tiyatro da m1, ${ }^{9}$ sinema ya da televizyonda mı devam edeceğine kendi karar vermek zorundadır. Bu kararı vermek yetmeyecek, hangi alanlara yoğunlaşacaksa o alana dair teknik bilgiye, entelektüel donanıma, hatta kendine has bir üsluba, kendi kendini eğiterek ulaşacaktır. Otodidaktik süreçler sanatın doğasında vardır, bu bağlamda sanatsal pratiklerin her biri sanatçı için kendi kendini eğitmenin önemli bir parçasıdırlar. ${ }^{10}$

Frank Camilieri, “Globalleşmiş Dijital Teknoloji Çağında Oyuncu Eğitiminin İncelenmesine Doğru" (Towards the Study of Actor Training in An Age of Globalised Digital Technology, Theatre, Dance and Performance Training) isimli makalesinde oyunculuk eğitiminin bir parçası olarak otodidaktizm'e değinmekte ve uzaktan eğitim, yeni medya ve öğrenme teknolojilerinin "güdümlü otodidaktizm" (guided auto-didactism) olarak adlandırdığı otonom süreçlere nasıl alan açtığı üzerine önemli tespitlerde bulunmaktadır. Camilieri’ye göre sahnede ya da stüdyoda öğretmen-öğrencinin fiziksel bir aradalığına ve müfredata bağımlı kurumsal oyunculuk eğitimi, global-dijital çağda yeni teknolojilerin gelişimi ile evrimleşmekte daha önce sadece kurumsal olmayan (alternatif, avangard ya da amatör tiyatrolarda vs.) ve ensemble'larda görülen otonom, otodidaktizme firsat veren ilişkilenme biçimlerinin bir devamı olarak melezleşmektedir. Bu doğrultuda "güdümlü otodidaktizm ve melezleşme" kavramları, kurumsal oyunculuk eğitiminde (konservatuarlar, oyunculuk bölümlerinde öğretmen-öğrenci rollerinin keskin bir şekilde ayrıldığı, kuralların ve müfredatın katı bir şekilde belirli olduğu eğitim alanında) bir "devrim" ya da "bozulma"dan çok bir süreç ve evrimin söz konusu olduğunu tespit etmek için işlev görmektedirler. ${ }^{11}$

Güdümlü otodidaktizm, kendi kendine öğrenme ile rehberli, bir yol haritası vasıtasıyla öğrenme biçimlerinin bir araya getirilip harmanlanmasını işaret etmektedir. Buradaki güdümlü kelimesi, danışılan metinlerden ya da görüntülerden çıkan uzmanlığın ya da deneyimin modellenmesini ifade eder. Dolayısıyla, kurumsal eğitimin online, uzaktan ya da diğer dijital teknolojilerle girdiği evrimsel ilişkide belirleyici olan, otodidaktik süreçlerdeki gibi öğrencinin yalnızlığında, tek başına düzenlediği, kendi kendini örgütleyen bir planlama ve öğrenme edimi değildir. Online olarak gerçekleştirilen atölyelere katılım gibi yoğun ve zaman kısıtlı

9 Tiyatroyu seçen ya da iş bulan bir oyuncunun işi burada da bitmez. Oyunculuk okullarında ağırlıklı olarak psikolojik gerçekçi bir eğitim alındığı göz önünde bulundurulursa, mezuniyet sonrası, fiziksel bir oyunculuğu temel alan bir toplulukta, absürd ya da epik metinlerin sahnelemelerinde yer alacak bir oyuncu için kendi kendini eğitme, otodidaktik öğrenme süreçleri kaçınılmazdır.

10 Kerry Williams, "Self Directed Learning in the Visual Arts", presentation, Flexible Futures in Tertiary TeachingProceedings of the 9th Annual Teaching Learning Forum, Perth, 2-4 February 2000. http://1sn.curtin.edu.au/tlf/ tlf2000/williams.html

11 Frank Camilleri, "Towards the Study of Actor Training in An Age of Globalised Digital Technology", Theatre, Dance and Performance Training 6:1 (2015), 16.

Erişim 15.09.2021 http://dx.doi.org/10.1080/19443927.2014.985334 
birliktelikler, özel olarak bir grup için organize edilmiş toplanmalar ya da özel bir tekniğin öğrenilmesi için bireylerin ya da topluluğun seçildiği organizasyonlar güdümlü otodidaktizm için bütünleyici çalışmalar olarak varolur. Bu bağlamda Camilieri’ye göre, güdümlü otodidaktizm, dijital çağda, bir tarafında otonom öğrenmenin, diğer tarafında ise öğretmen temelli öğrenmenin olduğu bir çizgi üzerinde, birbiriyle ilişkili bir çok öğrenme biçiminin olduğu geniş çaplı bir spektrum içinde ortaya çıkar. ${ }^{12}$

Camilieri'nin de altını çizdiği üzere, dijital çağın ortaya koyduğu yeni teknolojik olanaklar, öğrencinin daha efektif, bir rehber vasıtasıyla da olsa kendi kendini eğiten, kendi eğitim programını planlayan, bu doğrultuda zaman-mekan, müfredat ve öğretmen kısıtlamalarından özgürleşen bir öğrenci tipolojisini ve öğrenme biçimlerini işaret etmektedir. Bu doğrultuda online teknolojileri oyunculuk eğitiminde bir devrim ya da geleneksel-kurumsal eğitimin kazanımlarına dönük yozlaştırıcı-bozucu bir değişim olarak görmenin düşünce süreçlerimizi daraltmaktan ve konuya dair realiteden uzaklaştırmaktan başka bir çıktısı yok gibidir.

\section{Oyunculuk Eğitiminde Yeni Pedagojik Yaklaşımların Gerekliliği ve Online Eğitim}

Michigan Üniversitesi'nden Rob Roznowski, Amerikan Çalışma İstatistikleri Bürosu'nun (U.S Bureau of Labor Statics) verilerinden ve raporlarından yola çıkarak oyuncuların profesyonel çalışma yaşamına dair şu notları derlemiş:

"Sinema endüstrisindeki iş artışı, yeni filmlere ve televizyon şovlarına yönelik devam eden güçlü talepten kaynaklanacaktır... Prodüksiyon şirketleri gelecekte oyunculara için daha fazla iş sonucunu doğurabilecek "seç izle" (video on demand) ve online televizyon gibi yeni içerik dă̆ıtımı yöntemleri denemektedir... Streaming servisler ${ }^{13}$ gibi, yalnızca internet üzerinden erişilebilir platformların sayısı, bu platformlar için üretilen şovların sayısılla birlikte artacaktır. Sahne sanatları alanında çalışan oyuncuların, bu filmdekilere oranla daha yavaş bir iş büyümesi görmeleri beklenmektedir. Birçok küçük ve orta ölçekli tiyatro fon bulmakta zorlanmaktadır. Sonuç olarak performans sayısının azalması beklenmektedir.”14

Bu notların ABD' de oyunculuk mesleğini kuşatan koşullardan fazlasını tespit ettiği açıktır. Yirminci yüzyılın baş döndürücü teknolojik gelişmeleriyle birlikte tiyatronun yanında radyo, sinema, televizyon gibi medyalarda, reklam oyunculuğu, sunuculuk, spikerlik, seslendirmecilik gibi işlerle çalışma alanını genişleten oyuncular, dijital çağın dayattığı değişim ve dönüşümlerin

12 A.g.e, 22.

13 Streaming'in alıntıda geçen içeriğinin Türkçede bire bir karşılığında kullanılacak akış, gerçek zamanlı veri akışı vs. terimlerin aynı anlamı veremeyeceği düşünüldüğü için çevrilmemiştir. Alıntıda geçen içeriğiyle streaming servisler, internet üzerinde bir videoyu, müziği vb. şeyleri indirmek zorunda kalmadan ve tv'de olduğu gibi belirli bir zaman kısıtı olmadan istediğimiz an izleyebilmemizi sağlayan hizmetleri tanımlar. Netflix, Spotify, Amazon Prime, ülkemizdeki Gain gibi platformlar ve kanallar streaming servislere örnek gösterilebilir.

14 Rob Roznowski, "Transforming Actor Education in the Digital Age", Theatre Topics 25 (2015): E1.

Erişim 13.09.2021 http://dx.doi.org/10.1353/tt.2015.0028 
eşiğindedirler. Sosyal medya ağları, online platformlar, video oyunları, sesli kitaplar, podcast'ler, dijital sinema ve televizyon yapımları... Bu dev gelişmeler oyunculardan mesleki açıdan her geçen gün daha fazlasını talep etmektedir. Bu bağlamda oyuncular sahne ve gösterim sanatlarının yanında bu yeni medya alanlarının ihtiyaçlarına cevap verecek ölçüde mesleki bir donanıma, teknik bilgiye, farklı medyalarda mesleklerini icra edebilmelerini sağlayacak esnekliğe ve tecrübeye ihtiyaç duymaktadırlar. Ancak oyunculuk eğitimi veren kurumlar, oyunculuk bölümleri, konservatuarlar ve özel eğitim kursları bu gelişmelere cevap vermeye ne kadar hazırdır? Dünya genelinde az sayıda istisna hariç, bugün üniversite bölümlerinde ve konservatuarlarda oyunculuk eğitimini domine eden bakış geleneksel tiyatro eğitimine aittir. Ve geleneksel eğitim müfredatının "sahne için ses, sahne için hareket (beden), sahne için rol"15 eğitimi üzerine kurulu olduğu görülmektedir. Batıda daha fazla yer almakla birlikte, bizde daha çok seçmeli ders olarak karşılaşılan "Kamera Önü Oyunculuğu” gibi dersler, henüz sadece oyuncunun mesleki yaşantısını büyük ölçüde belirleyecek olan "çok yönlü oyunculuk profiline" bir giriş ya da başlangıç niteliğiyle sınırlı kalmaktadır. Diğer taraftan alıntıda raporlanan verilerden biri olarak "sahne sanatlarına ait performans sayısının giderek düşmesi ve sinema, dizi, reklam, dijital televizyonculuk gibi alanlardaki üretimlerin sayısının artması” gibi veriler, eğitimli oyuncuların ekonomik açıdan hayatlarını idame ettirebilmeleri için bu alanlara (da) yönelmek zorunda olduklarını, bir realite olarak önümüze çıkarmaktadır. Aldığı eğitim, sadece sahneye odaklanmış oyuncuların hayatlarını kazanacakları işlerde, kısa süreli de olsa kamera oyunculuğu ve audition eğitimi almış, film, dizi, reklam odaklı oyuncu koçlarıyla çalışmış oyuncuların karşında birçok açıdan dezavantajlı bir durumda kalmaları söz konusu olmaktadır. Bu doğrultuda, üniversitelerin oyunculuk bölümlerinde ve konservatuarlarda dijital çağın oyunculardan taleplerine cevap verecek, oyunculuk mezunlarının mesleki hayatları için kritik olan alanlarda gerekli donanımı sağlayacak, yeni eğitim içeriklerinin ve müfredatların tartışmaya açılması, bu tartışmalar sonrasında yeniden düzenlenmesi bir ihtiyaç olarak kendini dayatmaktadır.

Böylesi bir eğitim içeriğinin geliştirilmesi ve uygulanmasında dijital teknolojilerin ve online ortamların çok yönlü bir rol oynaması mümkündür. Birincisi, henüz yeni bir alan olarak bu tür eğitimleri verecek alanında uzman eğitmenlerin ve mesleki profesyonellerin sayılarının düşüklüğü hesaba katılacak olursa, online eğitimle ya da Kitlesel Açık Online Ders (MOOC) ${ }^{16}$ platformları işbilirliğiyle yapılacak eğitimlerin, aynı anda birçok öğrenciye, düşük maliyetlerle ulaşması söz konusu olacaktır. İkincisi, medyası gereği online eğitimin görüntüye dayanması

15 A.g.e, E-2.

16 Kitlesel Açık Online Kurslar (MOOC), herkesin kaydolabileceği ücretsiz çevrimiçi kurslardır. KAOD’ler, yeni beceriler öğrenmek, kariyer ilerletmek ve geniş ölçekte kaliteli eğitim deneyimleri sunmak için uygun maliyetli ve esnek bir yol sağlamaktadır. Dünya çapında milyonlarca insan, kariyer gelişimi, iş değiştirme, üniversite hazırlıkları, destekleyici öğrenme, yaşam boyu öğrenme, kurumsal e-Öğrenim gibi birçok başlıkta KAOD’leri kullanmaktadır. Nitelikli olanların yanında, niteliksiz, sadece kolay yolla para kazanmak için yapılan içeriklere rastlanılsa da KAOD’ler online eğitim için büyük bir alan açmaktadırlar. 
öğrencilere kamera çekimine dayanan sinema, TV programları, dizi, audition gibi alanlara ve pratiklere yönelik doğrudan deneyim kazandıracaktır. Üçüncüsü bu içeriklerin geliştirilmesinde, uluslararası ölçekte fiziksel açıdan bir araya gelmesi zor eğitim kurumlarının, eğitmenlerin ve meslek profesyonellerinin düşünce ve deneyim alışverişlerini Zoom, Microsoft Teams ve Moodle gibi teknolojiler üzerinden online toplantılarla gerçekleştirmeleri söz konusu olacaktır. Sonraki bölümde inceleneceği üzere, son on yıllık süreçte ve özellikle pandemi sonrasında online oyunculuk eğitimine dair üretilen pratikler, müfredatların yeniden incelenmesi ve yukarıdaki belirlenen ihtiyaçlara yönelik yeniden düzenlenmesine katkı koyacak yeterliliktedir.

\section{Online Oyunculuk Eğitimi Pratikleri}

Her ne kadar küresel pandemiyle yakıcı olarak gündemimize girmiş olsa da uzaktan ya da online oyunculuk eğitimi pratikleri dünya genelinde yeni bir şey değil. Dijital platformlarında oyunculuğa dair genel (klasik eğitim başlıkları, yöntemler vs.) ve mesleki spesifik başlıklarda (sinema, dizi, reklam oyunculuğu, audition pratikleri) oluşturulmuş video içerikleri, usta oyunculardan alınan master class eğitimleri, özel eğitim kurumlarının düzenlediği oyunculuk atölyeleri, üniversitelerin bünyelerinde oluşturdukları online eğitim programları ve ders içerikleri, online eğitime örnek oluşturan pratikler olarak şekillenmektedir. Birçoğunun eğitim içeriği olarak yetersiz ve kar amacıyla üretilmiş meta karakterine sahip olmaları bir yana, sürdürülebilirlikleri, teknolojik alt yapılarını günden güne geliştirmeleri ve yukarıda çizdiğimiz teorik çerçeveyi cisimleştirmeleriyle bu çalışmalar, online oyunculuk eğitimine dair önemli deneyimler olarak karşımızda durmaktadırlar.

\section{Kitlesel Açık Online Ders (MOOC) ve Diğer Platformlar}

Online oyunculuk eğitimi içeriklerine alan açan ve alanında uzman kişilerle o alanda eğitim almak isteyen kişilerin bir araya gelmesini sağlayan en önemli organizasyonlar olarak Udemy, Skillshare ve Lynda gibi dijital platformları görmekteyiz. Uzaktan ve online eğitimin bütün avantajlarını taşımasının yanında, kitlesel bir erişim sağlayan bu platformlar, bünyesinde barındırdıkları ders içeriklerini yalnızca önceden oluşturulmuş videolarla öğrenciye taşımamakta; çoğu zaman ödevler, modül geçme sınavları, öğrencilerin hazırladığı projeler ve öğrencilerin deneyimlerini paylaştıkları forumlar vasıtasıyla eğitimi boyutlandırmaktadırlar.

Bu platformlar arasında ön plana çıkan Udemy'de klasik oyunculuk eğitiminden (sahne bilgisi, ses, konuşma, hareket, metin analizi vs.) farklı oyunculuk yöntemlerine (Stanislavski, Meissner, Chekhov, Meyerhold gibi), sinema oyunculuğundan dizi ve reklam oyunculuğuna dair bir çok başl1kta sanatsal ve mesleki eğitim içeren online eğitimlere rastlamak mümkündür. ${ }^{17}$ Benzer bir şekilde, en çok izlenilen video platformu olan Youtube'da da birçok eğitim içeriğinin taşındığını görmekteyiz. Udemy kadar kullanışı olmasa da Youtube, imkanlar ve sınırlılıklar dahilinde kullanılabilecek araçlar içerisinde yer almaya devam etmektedir.

17 “Acting”. Udemy. Erişim 20 Eylül, 2021. https://www.udemy.com/topic/acting/?p=1 


\section{Master Class Sınıfları}

Eğitimle ilgili bir çok alanda olduğu gibi oyunculuk alanında da uzaktan-online eğitimin taşıdığı olanakları "fırsata çevirenler" ticari girişimciler olmuşlardır. 2015 yılında Stanford mezunu genç girişimci David Rogier silikon vadisinin önemli isimlerinden David Dearing'in sermaye desteğiyle online eğitim veren bir video platformu kurmuş, platformun oyunculuk alanındaki ilk eğitmeni Dustin Hoffman olmuştur. ${ }^{18}$ Masterclass.com web sitesiyle hayata geçen online eğitim platformu, kısa zamanda dünya genelinde büyük bir öğrenci kitlesine kavuşmuş, günümüzde 11 kategori altında yüzden fazla eğitim sınıfına sahip hale gelmiştir. Kısa zamanda Natalie Portman, Steve Martin, Samuel L. Jackson, Hellen Mirren gibi Holywood yıldızlarını da eğitmen listesine katan Masterclass.com, eğitim sektöründeki diğer girişimcilerinde iştahını kabartmış, kısa sürede onlarca benzeri online oyunculuk eğitim programı hayata geçmiştir. ${ }^{19}$ Bunlar arasında yine Udemy, Skillshare ve Lynda gibi dijital platformlarda bulunabilecek içeriklerin yanında, Miranda Harcourt gibi ünlü oyunculara oyuncu koçluğu yapmış isimlerin düzenlediği masterclass eğitimlerine ulaşmak mümkündür.

\section{Özel Eğitim Kurumları, Stüdyo ve Topluluklarda Online Eğitim Pratikleri}

Lee Strasberg Tiyatro\&Film Enstitüsü diğer online eğitim programlarından olan farkının altını şöyle çizmektedir:

"Yalnızca tek yönlü ögretim sağlayan dijital öğrenme platformlarının aksine, bu program tamamen interaktiftir ve öğrencilerimizin yetişmesi için optimize edilmiştir. Bu eşsiz eğitimin bir parçası olarak sunulan tüm sınıflar, workshoplar ve etkinlikler CANLI olarak düzenleniyor!'”. ${ }^{20}$

Enstitünün online derslerine baktığımızda, "Metot 101" ve "Metot Odakta" (Method in Focus) başlıklı birer aya yayılmış iki eğitim içeriğiyle karşılaşırız. Her iki eğitimin merkezinde Lee Strasberg'in oyunculuk yöntemi bulunmaktadır. Birinci ders içeriği Metot oyunculuğuna bir giriş niteliği taşımakta ve Strasberg'in "rahatlama”, "duyu belleği”, "konsantrasyon” egzersizleri üzerinde yoğunlaşılmaktadır. İkinci derste ise, Metot oyunculuğuna daha derin bir bakışla odaklanılmakta bu derse girmek için enstitünün Los Angeles ya da New York kampüslerinde eğitim görmüş olmak ya Metot 101 dersini online olarak almak gerekmektedir. ${ }^{21}$ Strasberg enstitüsü, bu iki online ders için Zoom video konferans platformunu kullanmaktadır.

Zoom'u kullanarak interaktif oyunculuk eğitimi düzenleyen kuruluşlardan bir diğeri olarak Actors Stüdyo’yu görmekteyiz. Actors Stüdyo'nun online oyunculuk kursları 1-5 gün arasında

18 Carina Chocano, "What is Masterclass Actually Selling”, The Atlantic, yayın tarihi Eylül 2020. https://www. theatlantic.com/magazine/archive/2020/09/what-is-masterclass-actually-selling/614200/

19 "Film, TV". Masterclass com. Erişim 23 Eylül, 2021. https://www.masterclass.com/

20 "The Lee Strasberg Theatre \& Film Institute . Erişim 24 Eylül, 2021. https://strasberg.edu/online/

21 "Method in Focus Online Acting Class". The Lee Strasberg Theatre \& Film Institute. 24 Eylül, 2021. https:// strasberg.edu/online/method-in-focus/ Online Acting Classes". 
değişen workshop'lardan oluşmaktadır. "Ekran Oyunculuğuna Giriş", "Yoğunlaştırılmış Ekran Oyunculuğu", "Shakespeare'in Sözcükleri..." gibi dersler bu kısa süreli workshop'larda Sarrah Hannah, Mel Churcher gibi eğitmenlerden online alarak verilmektedir. ${ }^{22}$ Bu workshop'lara daha yakından bakıldığında, kamera önü performası, çok boyutlu karakter yaratımı, prova süreçleri, kadraj bilgisi, audition hazırlama gibi ders içeriklerini görülmektedir.

Online eğitimlerini yine Zoom üzerinden veren diğer yap1, The Barrow Group (TBG) 1986'da New York' da kurulmuş bir topluluk ve eğitim merkezidir. İncelediğimiz diğer iki grupla karşılaştırıldığında daha fazla zamana yayılmış, çeşitli yaş gruplarına, türlere ve seviyelere göre düzenlenmiş eğitim içerikleri sunmaktadır. Sonbahar 2021 online eğitim programına baktı̆̆ımızda 13 ana kategoride sınıflandırılmış ders içerikleri görmekteyiz: Oyunculuk Programları, Oyuncular için Audition\& İş Sınıfları, Yeni Başlayan: Oyunculuk Sınıfları, Yeni Başlayan: Film/TV Oyunculuğu Sınıfları, Profesyoneller için Film/TV Sınıfları, Ücretsiz Deneme Sınıfları, Orta Seviye: Oyunculuk Sinıfları, Hareket Sinıfları, Profesyonel Oyunculuk Sınıfları, Özel Sınıflar, Genç Sınıflar: 10-13 yaş, Genç Sınıflar 14-17 yaş, Genç Sınıflar: 7-9 yaş. $\mathrm{Bu}$ kategorilere da yakından göz gezdirdiğimizde ise, bir yıl boyunca süren temel oyunculuk eğitimlerinden 6 haftalık kamera oyunculuğu ya da ses eğitimine, Alexander Tekniğini temel alan 8 haftalık hareket eğitiminden yine 8 hafta süren Shakespeare oyunculuğuna kadar daha birçok başlıkta ders içeriğiyle karşılaşmaktayız. ${ }^{23}$

\section{Üniversite Bölümleri, Konservatuar ve Özel Eğitim Kurumlarında Online Eğitim İçerikleri}

New York Film Akademisi, 1992 yılında Sinema eğitimi üzerine New York’ta kurulmuş, kısa sürede dünya genelinde birçok şubeye kavuşmuş bir özel eğitim kurumudur. Görüntü ve Performans Sanatlarında lisans ve yüksek lisans derecelerinde diploma ve çeşitli workshop eğitimleri sonrasında sertifikalar vermektedir. Oyunculuk alanında Sinema Oyunculuğu ve Müzikal Tiyatro Oyunculuğu olarak iki ayrı bölüme sahiptir ve bu bölümlerin online programları 1-15 haftada düzenlenen workshop'lardan oluşmaktadır. Sinema Oyunculuğu bölümünde Temel Oyunculuk Eğitimi’nin yanında, TV ve Film için Audition hazırlama, Ses Eğitimi gibi ders içerikleri mevcuttur. Stanislavski yönteminin temel alındığı oyunculuk eğitimi programının yanında "hareket ve doğaçlama" üzerine de çalışmalar yapılmaktadır. ${ }^{24}$

Bir diğer eğitim kurum olarak, Leeds Üniversitesi Tiyatro ve Performans bölümü, öğretim üyelerinden Jonathan Piches' in öncülüğünde oyunculuk eğitimine dair online bir eğitim içeriği oluşturmuştur. "Bilim ve Oyunculuğun Stanislavski Geleneği (Science and Stanislavski Tradition

22 “Online Screen Acting Courses”. Actors Studio. Erişim 24 Eylül, 2021. https://actorsstudio.co.uk/home/ online-screen-acting-courses/

23 "Acting Programs". The Barrow Group. Erişim 26 Eylül, 2021. https://www.barrowgroup.org/events/classschedule/category/fall-2021\#acting-programs

24 “Acting School”. New York Film Academy, Erişim 27 Eylül, 2021. https://www.nyfa.edu/acting-school/ 
of Acting)", "Vsevolod Myerhold" ve "Dağları Performe Etmek" (Performing Mountains)" gibi kitapların yazarı, Jonathan Pitches 2014 yılında Meyerhold’un Biomekanik etüdlerinden Tokat çalışmasını online eğitim içeriğine dönüştürerek Kitlesel Açık Online Ders (MOOC) plaformlarına yüklemiştir. Teorik ve pratik iki aşamadan oluşan ve eğitim katılımcılarının birbiriyle ilişki kurup, birbirlerinin pratiklerini değerlendirebildikleri bir workshop niteliği taşıyan bu eğitim içeriğgi, sadece oyunculuk eğitiminde uzaktan/online bir örnek oluşturmaz. Aynı zamanda, tiyatronun fiziksel ve performatif temellerinden yola çıkıp, oyunculuk eğitiminin uzaktan ya da online gerçekleştirilemeyeceği fikrini üreten algıya karşı, fiziksel tiyatronun kurucu cephesinden, Meyerhold ve Biomekanik yönteminden dolaylı bir cevap verir.

"Fiziksel Tiyatro: Tokatı Keşfetmek (Physical Theatre: Exploring the Slap) başlıklı online workshop'un birinci aşamasında katılımcılar yazılı olarak kendilerini tanıttıktan sonra, Pitches'ın önceden hazırladığ aktarımı gerçekleşir. Meyerhold'un bu yöntemi nasıl ve neden geliştirdiği, yöntemin gelişim tarihi, yöntemin etüdlerinin neler olduğu konusunda bilgi verildikten sonra, tokat atma etüdü çeşitli görsel materyaller, videolar ve animasyonlar desteğiyle ayrıntılı bir şekilde ele alınır. Arada interaktif mini bir quiz vardır ve aktarılan bilgiye dair beş tane soru sorulur. Doğru cevabı verene kadar denemeye devam eden katılımcılar, doğru cevabı bulduklarında Pitches'ın cevapla ilgili açıklamasına ulaşırlar. Bu bölümün sonunda katılımcıların programın içeriğine dair eleştirel düşüncelerine ve kendi aralarında tartışma yürütmelerine forum bölümünde firsat verilir. İkinci aşamada ise, ısınma ile başlanılan tokat etüdü animasyonlar üzerinden detaylı bir şekilde analiz edilir. Etüdün hareket mekaniği katılımcıların kolaylıkla kavrayabileceği ölçüde yalın ve detaylı olarak Meyerhold'un terminolojisiyle (Otkaz-Posil-Tochka) aktarılır. Bu aşamanın sonunda katılımcılardan Meyerhold'un çalışmalarını 1920'lerde kayda geçirip ifade etme biçimlerinden yola çıkarak yazılı, fotografik, çizimsel ya da film yoluyla kendi tokat etüdü çalışmalarını kaydedip, diğer katılımcılarla paylaşacak şekilde forum bölümüne yüklemeleri beklenir. Her katılımcının çalışması yoruma ve tartışmaya açıktır. ${ }^{25}$

Pitches'in Meyerhold üzerine yaptığı araştırmaların sonrasında gerçekleştirdiği bu online eğitim içeriği, sadece oyunculuk eğitiminde akademik bir formasyon sağlamayıp sahneleme pratiklerine de yol açacak şekilde kafa açıcı ve ilham verici bir kaynak görevi görmüştür. Örneğin, 2018 yılında Tahran'da sahneye konulan “Hyppolytus” oyunu Meyerhold'un Tokat egzersizleriyle çalışılmış, prodüksiyon süreci boyunca Pitches çalışmaları takip etmiş ve sonrasında başrol oyuncularından Niyavesh Nahavandi ile oyunculuk üzerine bir tartışma yürütmüştür. ${ }^{26}$

25 "Phsycal Theatre: Exploring The Slap". Future Learn. Erişim 29 Eylül, 2021. https://www.futurelearn.com/ courses/physical-theatre-exploring-the-slap

26 Mohtadi, Niloofar. "Jonathan Pitches on Physical Theatre's Ability to Transform Written Text". The Theatre Times. Yayın tarihi 31 Mayıs, 2020. https://thetheatretimes.com/jonathan-pitches-on-physical-theatres-abilityto-transform-written-text/ 
İncelediğimiz uzaktan ve online eğitim veren okullardan en ilginçlerinden biri olarak, "Rose Brufford Koleji Online Tiyatro Çalışmaları Bölümü’ lisans derecesi (BA) veren üç yıllık bir online eğitim programına sahiptir. Bölüm verdikleri online eğitim programlarını şöyle açıklar:

“...yaratıcı işlerde profesyonel bir kariyer sürdürmek ya da mevcut profesyonel konumların ilerletmek isteyenlere; tiyatro ve performans bilgilerini genişletmek ve beğenilerini gelişstirmek arayışında olanlara hitap ediyoruz. Ister tam zamanlı isterse yarı zamanlı olsun mezunlarımızı tiyatro ve performansa ilişkin konuların geniş bir yelpazesinin, pratikleri, tarihleri, bağlamlar ve yöntemleri içinde titiz bir temelle donatarak, sizlere tiyatro ve performans alaninda kapsamlı ama esnek bir eğitim programı sunmaya çalışıyoruz. "27

R. Brufford kolejinin bu doğrultuda üç yıla yayılan online tiyatro eğitimi, sıfırdan başlayan pratik bir oyunculuk eğitiminden çok zaten oyunculukla ya da tiyatronun diğer alanlarıyla ilişkili kişilere tiyatro sanatına dair bütünsel bir eğitim vaat etmektedir. Günümüzde tiyatro yapmanın koşulları, sahneleme estetiği, tiyatro işletmeciliği, menajerlik vs. temel derslerin yanında farklı oyunculuk ya da tiyatro yaklaşımlarından yola çıkarak metin analizinden oyuncunun dramaturjisine, makyajdan kostüme, performans türlerinden performatif oyuncunun bedenine, Stanislavski'nin, oyuncunun kendi kendine hazırlanma süreçlerinin analizinden Chekhov ve Brecht'in oyunculuk tekniklerine kadar geniş bir teorik ve estetik çerçeve öğrencilere sunulmaktadır. Bu bağlamda farklı ülkelerde, bölgelerde eğitimli ya da eğitimsiz oyunculukla uğraşan kişilerin online eğitim yoluyla estetik bakışları, politik duruşları, performans ve sahne bilgileri desteklenmekte, tiyatro oyunculuğunun sahne üzerinde rolünü icra etmekten ibaret olmayan zengin dünyasını kavratacak düşünsel bir zemin sağlanmaktadır. Brufford koleji, online eğitimini çok yönlü online araçlarla esnek bir eğitim içeriği sağlayan Moodle, Mahara ve Microsoft 365 gibi yazılımları kullanarak gerçekleştirmektedir. ${ }^{28}$

\section{Sonuç}

Pandemi gibi olağanüstü koşulların dışında da oyunculuk eğitiminde online derslerden faydalanabilir miyiz? Göründügü kadar basit olmayan bu sorunun cevaplanması için başta oyunculuk eğitmenleri olmak üzere, oyuncuların, oyunculuk öğrencilerinin ve konu üzerine kafa yoran akademisyenlerin yürüttüğü bir tartışma sürecine ihtiyaç duyulmaktadır. Böylesi bir tartışmanın ilk ve en önemli çıktısı, oyunculuk eğitimi üzerine katı yargıların ve genel geçer düşüncelerin yeniden gözden geçirilmesi olacaktır. Bu doğrultuda, oyunculuk eğitimini yalnızca sahne eğitimine odaklayan, sahne eğitiminin de ontolojik temelini yalnızca tiyatronun performatifliği üzerinden açıklayan ve bu doğrultuda online eğitimi ilk elden reddeden algının kırılmalara uğraması kaçınılmazdır.

27 Theatre Studies Online” Rose Bruford College. Erişim 30 Eylül, 2021. https://www.bruford.ac.uk/learn/ undergraduate-courses/theatre-studies-online/

28 “Theatre Studies Programme Specification” Rose Bruford College. Erişim 30 Eylül, 2021.https://www.bruford. ac.uk/wpcontent/uploads/2021/07/Theatre_Studies_Programme_Specification_2018_B.pdf 
Çalışmada irdelendiği üzere, ne tiyatro tek başına performatifliğinden ibarettir, ne de oyunculuk eğitimi sahne eğitimiyle bütünüyle özdeştir. Tiyatro ve oyunculuk eğitimi, her ikisi de performatifliğinin yanında mimetik birer etkinliktir. Ancak bu ortak yönleri de birini (oyunculuk eğitimini) ötekine (sahne eğitimine) sabit ve bağımlı kılmaz. Son kertede sahne, oyunculuk mezunlarının sanatlarını ve mesleklerini icra ettikleri alanlardan yalnızca birini, hatta günümüz koşullarında en dar olanını ortaya koymaktadır. Bu bağlamda oyunculuk eğitiminin mimetik yönü (ayna nöronların keşfinin de desteklediği gibi) zamana, mekana ve öğrenciöğretmenin fiziksel bir aradalığına bağımlı olmayan bir şekilde sahne eğitimini aşmaktadır. Daha önce alternatif tiyatro pratikleri, kitaplar, fotoğraflar, çizimler, filmler ve videolar vasıtasıyla öğrenmenin zamansal açıdan esnek olduğu, öğrencinin sahnede öğrendikleriyle sınırlı kalmadığı ve klasik öğrenci-öğretmen ilişkisinin kırıldığı otodidaktik süreçler, online teknolojilerin sunduğu olanaklarla birlikte mimetik öğrenmeyi başka bir boyuta taşımıştır. Bu boyut, daha önceki araçlara erişimi ve öğrenme süreçlerinin örgütlenmesini kolaylaştırmasının yanında tiyatro bölümlerindeki formal eğitimin işleyişini melezleştiren, öğretmenin öğrenme süreçlerindeki hegemonik varlığını bir rehbere, planlama ve uygulama süreçlerinde bir danışmana dönüştüren bir işlev görmüştür. Camilieri’inin önerdiği terimle söylenecek olursa online ders içerikleri otododidaktik eğitim ile formal eğitimi harmanlayıp "güdümlü bir otodidaktik eğitime" dönüştürmüştür.

Online eğitimin, formal eğitimle öğrencinin bütünüyle kendi kendini eğittiği otonom eğitim süreçleri arasına yerleşen bu güdümlü otodidaktik yapısı, oyunculuk öğrencilerinin mezuniyet sonrası profesyonel yaşamını destekleyen eğitim içeriklerinin kolaylıkla oluşturulup, dolaşıma sokulacağı başka bir avantajı daha getirmiştir. Oyunculuk öğrencisinin mezuniyet sonrası mesleki hayatını daha çok sinema, TV, dizi, reklam, sosyal ve dijital medya alanlarında sürdürecek (ya da sürdürmek zorunda) olmasının gerçekliğiyle, bu alanlara yönelik audition, kamera önü oyunculuğu, kadraj bilgisi gibi ders içerikleri online eğitim ile büyük olanaklara sahip olmuştur. Medyası gereği görüntüye dayanması, bu alanda uzmanlaşmış az sayıda profesyonele ya da akademisyene aynı anda çok sayıda öğrencinin ulaşımını sağlaması ve mesafeleri ortadan kaldıran yapısı ile online eğitim, yukarıdaki iş alanlarının talep ettiği "ç̧ok yönlü oyuncu profilinin" yetişmesine alan açmıştır.

Çalışmada örneklenen online eğitim programlarının paralı olması, bazılarının yüksek meblağlara ulaşması ve global pazarda kolay tüketilebilir meta karakteri taşımaları, onları nitelik açısından tartışılabilir bir konuma yerleştirmektedir. Ancak bu durum, teknolojik alt yapıları ve sürdürülebilirlikleri ile oluşturdukları deneyimlerin, ticari kaygılardan arınmış, bütünüyle öğrencilerin gelişimine ve öğrenme süreçlerinin niteliğine odaklanmış alternatif eğitim içeriklerine ilham veremeyeceği, akademik ve bilimsel bir çerçevede dönüştürülüp başka görevlerle donatılamayacağı anlamına gelmemektedir.

Oyunculuk eğitiminde Zoom, Microsoft Teams, Moodle gibi online teknolojilerinin bu ölçüde kullanılabilirliği kuşkusuz yeni bir olgu. Bu bağlamda üzerinde tartışılacak ya da referans alacak 
Türkçede ve yabancı dillerde üretilmiş akademik çalışmanın ve bilimsel verilerin yetersizliğinin altını çizmek gerekir. Erken sayılacak bu çalışma, bazı kritik noktalarda derinleşememe, kimi başlıklarda yetersiz ve yüzeysel kalma gibi riskleri de beraberinde getirmektedir. Ancak oyunculuk eğitimi veren bölümlerin, eğitim kurumlarının aralarındaki eşitsiz gelişim göz önünde bulundurulup oyunculuk eğitiminin yalnızca birçok olanağa sahip büyük şehirlerde gerçekleşmediği hesaba katıldığında bu risklerin alınması kolaylaşmaktadır. Her ülkede olduğu gibi ülkemizde de birkaç metropol şehrin haricinde oyunculuk eğitimi veren kurumlarda gelişkin müfredatlar oluşturmanın, alanında uzman eğitmenlere ulaşmanın ve öğrencileri deneyim kazanacakları profesyonel pratiklere dokundurabilmenin zorlukları ortadadır. $\mathrm{Bu}$ doğrultuda online teknolojiler, esnek bir eğitim sürecini organize etmeye, mesafeleri ortadan kaldırmaya, alanlarında uzman eğitimcilerin ve az sayıda mesleki profesyonelin aynı anda çok sayıda öğrenciyle buluşabilmesine olanak sağlamaktadır. Oyunculuk eğitimde firsat eşitliğine yaklaşabilecek olmanın motivasyonu, online teknolojilerin sunduğu olanakların tartışılmasını acil hale getirmekte, böylesi risklerin alınabilmesini de bir ölçüde meşru kılmaktadır.

\footnotetext{
Hakem Değerlendirmesi: Dış bağımsız.

Çıkar Çatışması: Yazar çıkar çatışması bildirmemiştir.

Finansal Destek: Yazar bu çalışma için finansal destek almadığını beyan etmiştir.
}

Peer-review: Externally peer-reviewed.

Conflict of Interest: The author has no conflict of interest to declare.

Grant Support: The author declared that this study has received no financial support.

\section{KAYNAKÇA / BIBLIOGRAPHY}

“Acting”. Udemy. Erişim 20 Eylül, 2021. https://www.udemy.com/topic/acting/?p=1

“Acting Programs”. The Barrow Group. Erişim 26 Eylül, 2021. https://www.barrowgroup.org/events/classschedule/category/fall-2021\#acting-programs

“Acting School”. New York Film Academy, Erişim 27 Eylül, 2021. https://www.nyfa.edu/acting-school/

Aristotle. Poetics, Translated by Anthony Kenny. Oxford: Oxford University Press, 1995.

“Autodidacticism”, erişim 03 Eylül 2021, https://educalingo.com/en/dic-en/autodidacticism

Camilleri, Frank. "Towards the Study of Actor Training in An Age of Globalised Digital Technology." Theatre, Dance and Performance Training 6:1 (2015): 16-29. http://dx.doi.org/10.1080/19443927.2014.985334

Chocano, Carina. "What is Masterclass Actually Selling." The Atlantic. yayın tarihi Eylül, 2020. https:/www. theatlantic.com/magazine/archive/2020/09/what-is-masterclass-actually-selling/614200/

Coşkun, Abdurrahman. “Ayna Nöronlar”, Bilim ve Teknik 557, Nisan (2014): 62-65.

"Film, TV”. Masterclass com. Erişim 23 Eylül, 2021. https://www.masterclass.com/

Fischer-Lichte. Erika, Performatif Estetik. Çeviren Tufan Acil. İstanbul: Ayrıntı Yayınları, 2016. 
Keysers, Christian. Empatik Beyin. Çeviren Aybey Eper. İstanbul: Alfa Yayınları, 2011.

Melberg. Arne, Theories of Mimesis. Cambridge: Cambridge University Press, 1995.

"Method in Focus Online Acting Class". The Lee Strasberg Theatre \& Film Institute. 24 Eylül, 2021. https:// strasberg.edu/online/method-in-focus/

Mohtadi, Niloofar. "Jonathan Pitches on Physical Theatre's Ability to Transform Written Text". The Theatre Times. Yayın tarihi 31 Mayıs, 2020. https://thetheatretimes.com/jonathan-pitches-on-physical-theatresability-to-transform-written-text/

"Online Acting Classes". The Lee Strasberg Theatre \& Film Institute . Erişim 24 Eylül, 2021. https:// strasberg.edu/online/

“Online Screen Acting Courses”. Actors Studio. Erişim 24 Eylül, 2021. https://actorsstudio.co.uk/home/ online-screen-acting-courses/

Phelan, Peggy. Unmarked: The Politics of Perfomance. London: Routledge, 1993.

"Phsycal Theatre: Exploring The Slap". Future Learn. Erişim 29 Eylül, 2021. https://www.futurelearn.com/ courses/physical-theatre-exploring-the-slap

Roznowski, Rob. "Transforming Actor Education in the Digital Age.” Theatre Topics 25 (2015): E1. http:// dx.doi.org/10.1353/tt.2015.0028

Sadeghi, Manijeh. "A Shift from Classroom to Distance Learning: Advantages and Limitations." International Journal of Research 4 (2019): 80-88.

http://dx.doi.org/10.29252/ijree.4.1.80

“Theatre Studies Online” Rose Bruford College. Erişim 30 Eylül, 2021. https://www.bruford.ac.uk/learn/ undergraduate-courses/theatre-studies-online/

"Theatre Studies Programme Specification” Rose Bruford College. Erişim 30 Eylül, 2021. https://www. bruford.ac.uk/wpcontent/uploads/2021/07/Theatre_Studies_Programme_Specification_2018_B.pdf

Williams, Kerry. "Self Directed Learning in the Visual Arts", presentation, Flexible Futures in Tertiary Teaching-Proceedings of the 9th Annual Teaching Learning Forum, Perth, 2-4 February 2000. https:// litec.curtin.edu.au/events/conferences/tlf/tlf2000/williams.html 